\title{
Review
}

\section{Building Resilience in Children to Prevent Social Aggression: The Principles of Behavioral Sciences}

\author{
Percival Longworth, MS [Pursuing] $]^{\prime *}$; Israel Kalman, NCSP²; Jennifer P. Peluso, PhD ${ }^{3}$ \\ 'Applied Psychology, Walden University, MN 5540I, USA \\ 2School Psychologist and Psychotherapist, NY, USA \\ ${ }^{3}$ Dean of Academic Affairs, Keiser University Flagship Campus, West Palm Beach, FI 33409, USA

\section{"Corresponding author} \\ Percival Longworth, MS [Pursuing] \\ Applied Psychology,Walden University, MN 5540I, USA;Tel. 91-729I879558; E-mail: rocky@equilibriumadvantage.com
}

\section{Article information}

Received: September II th 2019 ; Revised: September 30 th 2019 ; Accepted: October $3^{\text {rd }}$, 2019; Published: October $9^{\text {th }}$, 2019

\section{Cite this article}

Longworth P, Kalman I, Peluso J. Building resilience in children to prevent social aggression:The principles of behavioral sciences. Psychol Cogn Sci Open J. 20I9; 5(2): 42-49. doi: 10.17|40/PCSOJ-5-148

\section{ABSTRACT}

Most anti-bullying programs today are punitive. They rely heavily on schools enforcing procedures based on reporting, investigating, punishing, and labeling bullies. This paper challenges the notion that bullying behavior can be regulated effectively by legislative bodies and policymakers. Schools are communal ecosystems featuring unique social norms and behaviors. For example, in school, a student reporting a classmate to authorities may be labeled a 'snitch' because 'tattling' violates accepted social norms. Furthermore, the current legal definitions of bullying are confusing and complicated. In many cases, even trained lawyers have difficulty identifying acts of bullying. We suggest, the better approach to preventing bullying in schools, even the workplace, is to ground interventions using psychological frameworks to strengthen children's social and emotional competence. We contend that social development models provide the psychological frameworks society needs to develop emotionally stable children and adults while providing them with the internal fortitude to bounce back effectively from adverse situations like bullying.

\section{Keywords}

Bullying prevention; Social-emotional learning (SEL); Social development; Emotional strength; Social aggression; Anti-bullying; Self-awareness; Social-emotional competence; Power imbalance; Intentional; Columbine; Intervention.
\end{abstract}

\section{BUILDING RESILIENCE IN CHILDREN TO PREVENT SOCIAL AGGRESSION}

A ccording to Borgwald \& Theixos, ${ }^{1}$ despite the efforts to regAulate and prohibit aggressive behavior, incidents of bullying remain persistent in U.S. schools and throughout the world. In response to the mass shootings at Columbine High School in Colorado, virtually every school system in the U.S. has adopted an anti-bullying intervention program of one kind or another. Since 1999, 49 of 50 states have passed anti-bullying legislation ${ }^{2}$ and more than 193 countries have adopted the UN's Convention on the Rights of the Child UN resolution to prevent bullying in schools throughout the world. ${ }^{3}$ However, current laws and policies to reduce it are, at best, unclear and counter-intuitive. Bullying is such a comprehensive concept, suggests Cornell \& Limber, ${ }^{2}$ that it generates significant confusion regarding its meaning, severity, and relation to other antisocial behaviors such as harassment and social aggression. For example, the universal definition (legal, existing programs, policy, and institutional) for bullying includes three measures:

1. The aggression is intentional

2. A power imbalance exists between the victim and the perpetrator(s)

3. The hostility is repetitive

The Center for Disease Control and Prevention (CDC) recognizes this "tripartite" definition of social aggression. ${ }^{2}$ Herein lies the problem: First, "intentional aggression" (physical, verbal, and social hostility) is deliberately meant to cause someone harm. However, in its less volatile form, bullying can be virtually impossible to distinguish from typical childhood mocking, roughhousing, or name-calling. 
Second, size and strength of the bully notwithstanding, power imbalance is difficult to assess and establish, and it is an aspect typically ignored by victims reporting a bullying incident. ${ }^{2}$ Unfortunately, science has not developed tools for isolating and identifying power imbalance. To the untrained eye (teachers, administrators, and many policymakers), determining whether bullying has occurred is a virtual guessing game. Despite the inability to clearly establish power imbalance between two people, it is still a requirement. ${ }^{2}$

Thirdly, the inclusion of "repetitive aggression" in the definition of bullying further complicates enforcement of anti-bullying policies. As noted by Cornell and Limber, ${ }^{2}$ repetitive behavior is vital in classifying an act of bullying, but it places the liability on observers (teachers, administrators, and counselors). When a victim reports an act of "bullying," how does the current legal definition provide the precise framework for educators to offer an effective remedy when so much of its definition is so difficult to prove?

This current state has netted a system in which 86 percent of the anti-bullying programs fail to reduce bullying at all, and only 14 percent provide minimal results. ${ }^{4}$

What if the aggressive behavior was intended to cause harm, but lacked power imbalance, repetition, or both? Unfortunately, existing anti-bullying legislation and policies are too ambiguous to provide a clear-cut answer. Not only are schools saddled with a complicated definition of bullying, but educators must also sort through which federal and state laws apply to a student who reports bullying. ${ }^{2}$

While Columbine sparked a national effort to end bullying, the more pressing question is does current policy and legislative processes provide an effective solution? Oddly, little research has been conducted to determine the execution of these laws and policies, and what affects (financial, climate, culture, etc.) they have on curbing bullying in our schools. ${ }^{2}$ Many researchers and anti-bullying experts believe the answer to the current bullying dilemma is outside our legal and legislative systems.

\section{DO SOCIAL DEVELOPMENT MODELS OFFER A SOLUTION?}

Schools are communal ecosystems comprised of distinct sets of socially acceptable and unacceptable norms and behaviors. For example, in school, reporting a classmate to authorities may be considered a violation of existing social standards. Conversely, slapping someone on the butt might be considered a form of bullying, even sexual harassment, but in certain contexts and situations, a teammate for example, this act may be considered a suitable congratulatory gesture. However, today's legal and policy systems fail to distinguish between real hostile behavior and other minor forms of social aggression, according to Kalman. ${ }^{5}$ As much as we would like to isolate children from potentially adverse situations, especially at school, many experts suggest the better approach is to provide kids with the social skills they need to thrive in any setting. ${ }^{6-8}$ Still, few current anti-bullying programs offer theoretical frameworks to enhance social and emotional skills in children. ${ }^{9}$

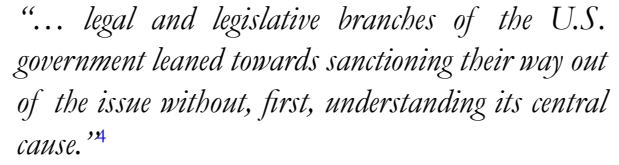

Moreover, most anti-bullying programs require children to report peers to adults, including teachers and other school officials. ${ }^{10}$ Unfortunately, children who "tattle" on classmates may be labeled informants or "snitches" by their fellow students for acting in ways that are counter to the school's "social" code of conduct, so many victims are less likely to report an incident. Additionally, when reported to "authorities," bullies consider themselves to be the victim; consequently, their retaliation and efforts for revenge tend to be much harsher than the initial act. ${ }^{11}$

So, what are the cognitive and emotional undertones that spark or prevent bullying and how do teachers, counselors, administrators, students, and parents mediate more efficiently? Social development models that include social-emotional learning (SEL) offer suggestions for reducing aggressive social behavior:

- Help kids develop self-awareness-foster their ability to recognize their feelings, thoughts and other influences on their behavior. This aspect includes acknowledging one's personal strengths and weaknesses. Children with a high-level of self-awareness understand how their ideas, feelings, and actions interconnect. $^{12}$

- Children also need skills to help them regulate their emotions; these include thoughts and behaviors, as well as managing stressful situations and controlling instinctual impulses (flight or fight). Students who develop this strong sense of self-management are much more likely to exceed academic and personal goals. ${ }^{12}$

- Teaching children social-emotional competence provides them with the ability to accept the perspectives of other people regardless of culture, economic status, ethnicity, or religion. These developmental qualities make it possible for kids to empathize and grasp social and ethical norms, which are essential elements for successfully creating positive relationships with others. $^{12}$

- Because a school is a social setting, reducing social aggression means providing students with tools to listen and communicate effectively, navigate conflict constructively and offer help to others, or seek it when the need arises.

- Finally, to build a kinder, gentler school environment, kids need the capacity to make respectful choices that take into consideration, safety and security, ethics, and potential consequences for their actions including the well-being of others. ${ }^{12}$

Children who develop positive self-awareness, self-management, social mindfulness, relationship and decision-making skills are more likely to become self-reliant and confident in dealing with difficult situations, not only in school but throughout their 
life. ${ }^{9}$ Based on a McCormick ${ }^{13}$ study, in schools where this model of learning exists, teachers and administrators spend less time managing anti-social behavior and more time teaching. ${ }^{13}$ Additionally, through effective SEL programs, academic performance typically improves and kids develop the capacity to recover quickly from adverse situations like bullying. Students who develop competent social and emotional skills tend to be better adapted to school, the classroom, and at home. ${ }^{12}$ Consequently, we recommend focusing on building social and emotional strengths within children and, at the same time, providing parents and teachers with the tools to guide, mentor, and teach students how to thrive in virtually any social situation.

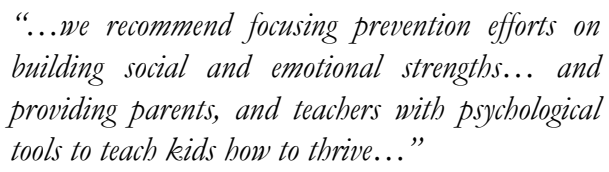

\section{WHAT IS BULLYING AND WHY DOES IT OCCUR?}

Typically, experts agree that bullying is a relational-based form of aggression, which includes various types of physical or verbal actions meant to humiliate, dominate, or oppress another person. Explicit bullying is physical hostility focused towards peers with the intent of causing or threatening physical harm. ${ }^{14}$ On the other hand, relational bullying, the most common form, consists of verbal aggression such as name calling, threats or insults. These indirect forms of social aggression also include gossiping, spreading rumors, and social exclusion. ${ }^{15}$

The most common theme is that bullying consists of physical and verbal attacks targeted towards a victim or victims, by one or more students (power imbalance) taking place over an extended period. ${ }^{16}$ For example, one child may begin harassing an unpopular student, and then a few friends urge the aggressor on while others sometimes stand by and passively observe. In either case, this power differential means victims often feel incapable of stopping or even preventing the attack. Consequently, victims in this example may become an ongoing target because they are either incapable of defending themselves, or more often, lack the social skills to resolve the situation calmly. ${ }^{17}$ This power imbalance and constant targeting separate bullying behavior from the odd fight, pushing and shoving match, or teasing that commonly takes place among children of similar age and size. ${ }^{18}$

"... typical bullying targets are students who are perceived as different, weak, shy... including gays, lesbians, people of color or lower socioeconomic status..”

A vast amount of research indicates that the typical targets of bullying are those students perceived by classmates as different, weak, or socially shy. ${ }^{11}$ As Karin Lehnardt suggests, ${ }^{19}$ these include gays and lesbians, people of color, students of lower socioeconomic status and various religious sects. Even being considered too good by classmates ("teacher's pet") is a formula for being bullied. ${ }^{11}$
In social settings, such as school, children typically jockey for power and status, so some aggressive behavior is a relatively normal childhood behavior. ${ }^{11}$ Nevertheless, for the 5 to 15 percent of children who are chronically bullied, ${ }^{20}$ this form of social aggression is anything but normal. Being frequently bullied can have devastating effects throughout a child's lifetime. As a consequence of failing with peers and teachers, both bullies and victims can become withdrawn, socially anxious, aggressive, and fearful, which puts them at risk of developing even more serious problems as they navigate through adolescence and into adulthood. ${ }^{11}$

In fact, in one longitudinal study conducted by Olweus with more than 700 boys from Stockholm, 36 percent of bullies at ages thirteen to sixteen received three additional bullying convictions between the ages of sixteen and twenty-four. ${ }^{21}$ Furthermore, in a Cambridge Study of Delinquent Development, boys who bullied at age fourteen tended, in their mid-twenties, to have children who were also bullies. ${ }^{21}$

So, how do we protect children from the dangers of bullying? As previously noted, reporting bullies to adults or authorities may backfire and lead to more severe reprisals. ${ }^{11}$ Among children who are already socially apprehensive or anxious, "standing up" physically or verbally to confront a bully may also be counterintuitive. ${ }^{11}$ While a victim's retaliation against a bully may decrease his or her anxiety level temporarily, it may also require him or her to become physically aggressive, which could run counter to their personality, or personal values. Moreover, this "tit for tat" strategy may prolong or escalate the targeted aggression.

Unfortunately, for school kids, bullying is such an effective way of gaining and maintaining social status. Bullying is typically present at every age-it is somewhat like a severe storm that is not in our power to totally control. ${ }^{11}$ Nonetheless, we can shield children from the adverse effects of bullying by instilling in them a feeling of self-efficacy (resilience)-the sense that they can control the situation. ${ }^{11}$ In creating the curriculum for the Be Strong bullying prevention program, our goal was to design a school-wide program to build children's interpersonal competencies and, at the same time, provide them with the confidence to overcome the challenges associated with bullying (and other adverse events) using resilience and social and emotional learning theories.

\section{WHY ARE CURRENT ANTI-BULLYING INTERVENTION PRO- GRAMS FAILING?}

Bullying intervention programs are well intended. For example, the Olweus Bully Prevention Program provides school administrators with plans for conducting assemblies early in the academic year to discuss the school's stance on bullying. ${ }^{11}$ In the Olweus program, school officials are encouraged to form bullying prevention committees that include student participants from each grade. Teachers and students are taught to recognize bullying behavior and take appropriate steps to identify, investigate, report, and punish offenders. One of the main goals of this program is to create a school-wide policy against all forms of peer abuse. ${ }^{1}$ But, do these kinds of programs work? The majority reduce bullying only mar- 
ginally-20 to 23 percent-and reduce victimization between 17 and 20 percent. $^{22}$

\section{"... the US Department of Education threatened to cut funding in schools failing to investigate and address every bullying complaint... America's legal and political systems laid intervention and prevention directly on local school systems."}

After Columbine, state, federal, and local policymakers acted quickly to protect children and create a safe and secure school environment. ${ }^{5}$ Washington D.C. and nearly every state in the U.S. adopted legislation against bullying, passing mandates for punishing offenders and requiring schools to enforce strict codes of conduct. In fact, the U.S. Department of Education declared that funding for general school programs would be cut in schools failing to investigate and address every bullying complaint. ${ }^{5}$ Consequently, the American political and legal systems laid intervention and prevention directly on local school systems by demanding that they eradicate bullying. ${ }^{5}$ Today, many "bullying" policies include an elaborate punitive systems to discourage bullies from exercising their power over weaker and often younger classmates. However, David Myers suggests, ${ }^{23}$ that this current punitive approach fails to recognize a fundamental aspect of human nature-our innate desire to belong and develop meaningful relationships with others. Think about this for a moment. In a legal system, the rules are black and white; there tend to be few gray areas. For example, a child commits an act of social aggression in school; the child is apprehended, investigated, labeled a "bully," and punished. However, school is a social system, not a legal one, and most psychologists agree that the cause of bullying is filled with lots of gray areas and murky waters. Would a more sensible approach to prevent bullying include insight into the natural laws of human behavior? We believe the answer to be a resounding yes! Leading cognitive and behavioral scientists know that social systems, such as schools, are comprised of many different integrated pieces.

Even well-intended interventions can have unintended effects; consequently, psychologists do not presume that because the intent is honorable that results will only be positive. Scientists consider potential adverse outcomes before developing the appropriate responses or interventions. Passing laws and policies that make bullying illegal is an exceedingly harsh intervention with grim consequences for children, their parents, teachers and school administrators. Especially when the definition of bullying is so vague. The current system identifies and punishes bullies, schools get sued, and, in the end, the system pits parents and teachers against each other to avoid the appearance of criminal negligence. Still, research indicates that even the most highly-regarded intervention programs not only fail to stop bullying, but they also leave schools sitting ducks for parents armed with lawyers.

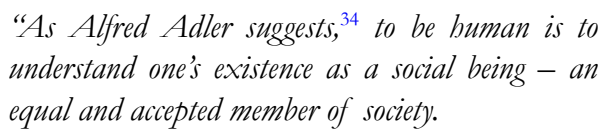

It bears repeating that schools are social settings featuring a unique set of norms for social behavior. Many of today's anti-bullying initiatives center their efforts on pledges, investigating, labeling offenders "bullies," and punishment that include expulsion from school. However, it is not just these types of policies that fail to reduce bullying, gold-standard programs that set the bar for full-school intervention programs are producing poor results, as well. Why? Based on a literary review of more than 2,000 studies and articles, we have identified five factors that may inhibit the success of many of today's anti-bullying programs:

- Legal and legislative action-bullying is a socially based phenomenon, and we are attempting to legislate our way out of it, including all the appropriate penalties. Constraining when and where it can occur will not address the underlying causes of social aggression or prevent it from occurring.

- An underlying motivation that drives human behavior is the need to belong and to develop meaningful relationships with others. As Alfred Adler suggests ${ }^{24}$ to be human is to understand one's existence as a social being-an equal and accepted member of society. This sense of belonging is crucial for positive individual mental health. Well-being grows when children feel they belong to a larger circle of existence; this feeling of social safety is a fundamental aspect of human life. ${ }^{25}$ Even bullies act out a desire to "connect" with others, or out of frustration when peers reject their attempts to connect. Practices and programs that vilify a bully — without addressing his or her own need to belong - at best, offer an imperfect solution. Anger and aggression in children is a complex issue; enforcing laws, rules, and institutional regulation is not the answer. We are taking a page from John Gottman ${ }^{26}$ to suggest a slightly different approach: train parents and teachers to become emotional coaches, so children develop the skills to prevent and overcome socially aggressive situations such as bullying. ${ }^{27}$

"Interventions should... assess the level of bullying
in school, offer mechanisms to reduce it, provide
the means to change behavior, accurately measure
results, and evaluate program elements..."

- Social-emotional learning (SEL)-few bullying intervention programs emphasize providing children and adults with the means to overcome stressful situations by fostering self-efficacy, emotional strength, and resilience. ${ }^{28}$ We view this as a fundamental foundation for successfully reducing social aggression. - Home environment-parents play a vital role in preventing bullying, so parental inclusion is imperative. Families can foster emotional security, belonging, and connectedness in their children. Furthermore, parents who create secure relationships with children also promote exploration, self-efficacy, learning and social development, which are tools needed to help children successfully adapt to and overcome stressful situations. ${ }^{29}$ Typically, a child's exposure to bullying occurs first at home, then at preschool and kindergarten. Consequently, to begin building resilience in children, we should consider integrating social and emotional training into school curriculum and home at an earlier age. ${ }^{4}$

- Research-few authors of anti-bullying programs offer the- 
oretical mechanisms of change or identify which elements if any, result in a reduction in social aggression. ${ }^{17}$ Theoretical frameworks help researchers to establish internal and external validity and provide the impetus for understanding the intervention's ability to generate the desired impact.

In our example, we propose reducing incidents of bullying by improving a child's self-efficacy. ${ }^{30}$ There is too much research and too many experts who acknowledge that anti-bullying programs as they stand today are ineffectual and that the way their efficacy is measured fails to provide proper scientific rigor. ${ }^{22}$ Creating more efficient anti-bullying programs means starting with a fundamental understanding of the factors that are known scientifically to reduce aggression and increase prosocial behavior. ${ }^{30}$ Then, we need to use methodically, rigorous research processes to assess and analyze program outcomes. With this in mind, we advocate for social-emotional learning components that offer students, parents, teachers, counselors, and administrators the quantifiable instruments for understanding and overcoming adverse situations in a positive, caring and humane manner.

\section{WHAT DO PSYCHOLOGICAL AND ACADEMIC COMMUNITIES RECOMMEND? |}

Ideally, an effective anti-bullying program would get students to change their attitudes and behavior towards each other (as well as toward bullying) as opposed to just recognizing and reporting bullying to authorities. Interventions should be designed to assess the level of bullying in school, offer mechanisms to reduce it, provide the means to change behavior, accurately measure results, and evaluate program elements and their ability to spark and sustain change. ${ }^{30}$ From this perspective, we recommend basing interventions on prevailing psychological theories. Scientific principles help us to identify the essential elements that lead to changes in attitudes and behaviors; to the contrary, most anti-bullying programs today focus on legal enforcement. ${ }^{5}$

In their attempt to address every potential cause of bullying, most programs fill schools with posters containing catchphrases, implore bystanders to jump in, define specific acts of social aggression, and encourage students to report bullies to authorities. ${ }^{5}$ From this standpoint, it is nearly impossible to identify which specific program elements reduce bullying and foster the desired behavioral change because most lack an expressed theoretical foundation. $^{30}$

This fragmented approach may lead to some reductions in bullying; however, often, it results in expending extraordinary sums of money and effort without the promise of long-term success. ${ }^{5}$ Frequently, this approach exacerbates the problem by reinforcing bullying behaviors instead of preventing them. For instance, zero-tolerance policies, standard in many schools today, are linked to an increase in a different type of bullying-covert forms. ${ }^{1}$ In our attempts to prohibit bullying, we have driven it underground. Covert bullying is becoming more widespread and imaginative. ${ }^{1}$ For instance, the spreading of rumors and hostility through cyberbullying is increasing, and incidents of physical aggression have moved from the classroom and playground to the bathrooms and other isolated areas of school out of plain sight. ${ }^{1}$

Scientific experts also recommend that anti-bullying interventions take place at the appropriate level. ${ }^{30}$ As a case in point, a significant amount of research indicates that social aggression begins as early as four years of age and is also prevalent in kindergarten; however, most anti-bullying programs target older elementary, middle school and high school students. ${ }^{9}$ Experts also suggest that the size and depth of the intervention should address the extent of the change needed. In other words, program duration (length of time) and intensity (frequency of sessions) should relate closely to the desired behavioral change.

For example, Rotheram-Borus created an effective intervention program for runaway children called "Street Smart". ${ }^{31}$ The program provides kids with access to healthcare, condoms, and a series of 10 skill-focused sessions based on social learning theory. In this example, the more sessions kids attend, the better the results. ${ }^{30}$ Bullying has existed throughout various levels of society for centuries; consequently, lasting change to reduce it is more likely to occur with sustained intervention. In these instances, when programs continue over an extended period, even when follow-ups are informal, intervention programs are more apt to reduce the problem. ${ }^{30}$ In this regard, bullying prevention programs should be considered long-term and planned accordingly.

\section{"Home is a child's early learning environment; it provides them with countless hours of interaction that shape their adaptive skills, self-efficacy, and social and emotional competence. "29}

Many bullying prevention experts recommend including parent training in social and emotional management in an interventions program's curriculum. Since exposure to social aggression typically begins at home, this seems to be a logical part of a successful intervention. However, few anti-bullying intervention programs include a coherent, structured parenting component. For example, the Olweus Bullying Prevention Program (OBPP) includes school-wide and classroom training modules, classroom curriculum, and bullying questionnaires. ${ }^{32}$ OBPP is a whole-school program that features school, classroom, individual, and community-level components. These modules emphasize enforcement, rules, bullying definitions, supervising student activities, and meeting with parents, teachers, and community leaders, and not social and emotional development. ${ }^{32}$

Burkhart et $\mathrm{al}^{14}$ suggest Parenting programs can be an enormously effective means to reduce internalizing and externalizing problems in children. According to Hoffman's theory of moral internalization, ${ }^{14}$ children learn discipline, empathy, resilience, the concept of justice, and consideration of others from their parents first. Consequently, parents need a fundamental understanding of bullying and the ability to recognize if and when their child becomes a victim. However, experts also suggest that family and child resilience is intertwined. Home is a child's early learning environment; it provides them with countless hours of interaction that 
shape their adaptive skills, self-efficacy, and social and emotional competence. ${ }^{29}$ These are the principal components we used to create the Be Strong Bullying Preventionand Resilience Program.

Researchers also suggest that school climate plays a vital role in preventing bullying and improving academic performance. These dimensions include the commitment by school officials to educate, instruct, and develop trusting relationships with staff, community members, parents, and students. In 2014, Hajduova \& Andrejkovic found that in schools that convey their policies towards bullying clearly, and create an environment of inclusion and cooperation among students and faculty members have shown a significant reduction in bullying incidents according to. ${ }^{33}$ We support making tools available to school administrators, counselors, and teachers for educating, clarifying policies, motivating collaboration, and supporting students on both social and emotional levels.

\section{"...by improving their social-emotional skills, we can provide children with the internal strength they need to overcome challenges like bullying, build secure relationships with others, and excel academically. "12}

\section{WHAT IS RESILIENCE AND CAN WE TEACH IT?}

Though not considered a character trait per se, resilience refers to the ability to successfully adapt to a situation when confronted by significant adversities, challenges or disruptions such as bullying, harassment, discrimination, and natural or human-made disasters. ${ }^{29}$ RAND, a prominent global research and analytics firm, groups factors related to resilience into individual, family, organizational (school, work, etc.) and community categories. ${ }^{29}$ Individual classes include positive coping (practical problem solving), buoyancy (positive affect), positive thinking (reframing thought), setting realistic expectations (interpreting situations accurately), and behavioral and emotional regulation. ${ }^{34}$ Resilience training programs used by the military and first responder groups typically include these components borrowing theoretical frameworks from cognitive and behavioral sciences. ${ }^{34}$

Resilience depends on internal assets such as possessing a calm demeanor, being self-aware, able to regulate emotion, and to empathize with others. As previously noted, just like math and geography, resilience can be taught, reinforced, and refreshed through social and emotional learning (SEL). SEL provides the pathway to educate children so they can recognize and control their feelings more efficiently, manage stress, resolve conflict peacefully, and make responsible decisions. In other words, by improving their social-emotional skills, we can provide children with the internal tools they need to overcome challenges like bullying, build secure relationships with others and excel academically. ${ }^{12}$ Fortunately, during the past twenty years, educators have gained access to a multitude of SEL models designed to enhance the development of social and emotional wellbeing in children.

For example, Bullies to Buddies, a program developed by Izzy Kalman and the Be Strong Bullying Prevention and Re- silience Program, created by the authors of this paper, impart social-emotional skills so kids can cope and bounce back quickly when confronted with stressful situations. In other words, the programs teach children to frame adversity, such as being bullied, as a challenge and then provides them with the social mechanisms they can apply to move beyond it positively. These include acknowledging responsible choices and appropriate behaviors; recognizing personal strengths, keeping emotions in check, and being aware of other people's perspectives. Typically, children who can understand and manage their emotions effectively perform better academically; they form healthier relationships with peers and adults, set realistic expectations and make responsible and ethical decisions. ${ }^{12}$ Why is this important? Because children equipped with social and emotional competency tend to adjust to school and classroom environments more effectively. Their ability to focus energies on academic assignments is stronger compared to students exhibiting poor social skills. ${ }^{12}$

Furthermore, in classrooms with established SEL programs, teachers spend much less time managing volatility, and this includes investigating and apprehending bullies. ${ }^{12}$ In addition to a reduction in antisocial behavior, greater social and emotional competence correlates to an increased likelihood of attending college, career success, and better overall psychological health. What is even more encouraging is that a recent meta-analysis of more than 80 school-based SEL intervention evaluations illustrates that sustaining positive outcomes for students over time is possible. ${ }^{12}$

\section{CONCLUSION}

We are not advocating for the abandonment of existing anti-bullying programs. In severe cases of bullying, perpetrators should be apprehended and punished appropriately. Children also need a support system that includes the opportunity to report social aggression that causes physical or emotional harm to the proper authorities, but they also need an internal developmental system that helps them to address the issue on their terms. Meaning, by understanding social constructs within the school environment and developing social and emotional competence, we can prepare children to handle almost any unfavorable situation. ${ }^{9}$

One of the first ethical codes of conduct we learn as psychological professionals is to do no harm (APA, n.d.). Still, our profession promotes anti-bullying policies that, according to a significant body of evidence, produce minimal results. The current system suggests that targets are powerless; we need to protect them at all costs. After all, kids deserve the right to attend school in a bully-free, safe environment. While we agree in principle, we also know that establishing dominance through relational aggression has been in existence since the dawn of time; it is an instinctual survival behavior. $^{5}$

From this perspective, legislating or setting a policy to prevent bullying runs counter to human nature and presses educators into the role of enforcer, judge, and jury at the risk of their school's legal peril. As psychologists, we are also taught to 
avoid taking client sides and more importantly, labeling people, but today's anti-bullying establishment requires us to do both. Unfortunately, this victimization rationality pits aggressors against targets, teachers against parents and students, administrators against policymakers, and the legal system against the educational system. This current state has netted a system in which 86 percent of the anti-bullying programs fail to reduce bullying at all, and only 14 percent provide minimal results. ${ }^{4}$

Scientists know that we cannot possibly control mother nature; in other words, a natural disaster will inevitably strike at some point somewhere in the world. However, like bullying, we can provide people with the means to prepare and mitigate the unexpected harm mother nature often perpetuates. As a result, we are recommending a fundamental paradigm shift in today's anti-bullying interventions. Instead of focusing on protection and punishment, center the foundation for prevention on preparation and personal development.

In other words, help kids cultivate, identify, and tap into their social and emotional strength so they can persevere and thrive in hostile or challenging situations - this is the heart of what we recommend and support.

\section{CONFLICTS OF INTEREST}

The authors declare that they have no conflicts of interest.

\section{REFERENCES}

1. Borgwald K, Theixos H. Bullying the bully: Why zero-tolerance policies get a failing grade. Social Influence. 2013; 8(2-3): 149-160. doi: 10.1080/15534510.2012.724030

2. Cornell DG, Limber SP. Law and policy on the concept of bullying at school. Am Psychol. 2015; 70(4): 333-343. doi: 10.1037/ a0038558

3. Cornu C. Preventing and addressing homophobic and transphobic bullying in education: A human rights-based approach using the United Nations Convention on the Rights of the Child. Journal of LGBT Youth. 2016; 13: 333-343. doi: $10.1080 / 19361653.2015 .1087932$

4. Fox BH, Farrington DP, Ttofi MM. Successful bullying prevention programs: Influence of research design, implementation features, \& program components. International. Journal of Conflict \& Violence. 2012; 6(2): 273-283. doi: 10.4119/UNIBI/ijcv.245

5. Kalman IC. Why psychology is failing to solve the problem of bullying. International Journal on World Peace. 2013; 30(2).71-97.

6. Hymel S, Swearer SM. Four decades of research on school bullying: An introduction. Am Psychol. 2015; 70(4): 293-299. doi: $10.1037 / \mathrm{a} 0038928$
7. Rodkin PC, Espelage DL,Hanish LD. A relational framework for understanding bullying: Developmental antecedents and outcomes. Am Psychol. 2015; 70: 311-321. doi: 10.1037/a0038658

8. McDougall P, Vaillancourt T. Long-term adult outcomes of peer victimization in childhood and adolescence: Pathways to adjustment and maladjustment. Am Psychol. 2015; 70(4): 300-310. doi: $10.1037 / \mathrm{a} 0039174$

9. Jenson JM, Brisson D, Bender KA, Williford AP. Effects of the youth masters prevention program on patterns of bullying and victimization in elementary and middle school. Social Work Research. 2013; 37(4): 361-372. doi: 10.1093/swr/svt030

10. mnCornell DG, Limber SP. American Psychological Association. Do U.S. laws go far enough to prevent bullying at school? Web site. https://www.apa.org/monitor/2016/02/ce-corner. Accessed September 10, 2019.

11. Belsky J. Experiencing the Lifespan. $2^{\text {nd }} \mathrm{ed}$. New York, USA: Worth Publishing; 2010.

12. OberleE, Domitrovich CE, Meyers DC, Weissberg RP.Establishing systematic social and emotional learning approaches in schools: A framework for school wide implementation. Cambridge Journal of Education. 2016; 46(3): 1-21. doi: 10.1080/0305764X.2015.1125450

13. McCormick MP. General introduction. In: Insights into Social-Emotional Learning and Academic Achievement: An Approach for Strengthening Causal Inference. MI, USA: ProQuest LLC; 2015: 1-24.

14. Burkhart KM, Knox M, Brockmyer J. Pilot evaluation of the ACT raising safe kids program on children's bullying behavior. Journal of Child \& Family Studies. 2012; 22: 942-951. doi: 10.1007/ s10826-012-9656-3

15. Graham S. Bullying: A module for teachers. Web site. http:// www.apa.org/education/k12/bullying.aspx. 2016. Accessed September 10, 2019.

16. Moon B, Hwang H-W, McCluskey DM. Causes of school bullying: Empirical test of a general theory of crime, differential association theory, and general strain theory. Crime \& Delinquency. 2011; 57(6): 849-877. doi: 10.1177/0011128708315740

17. Reyes JA, Elias JM. Fostering social-emotional resilience among Latino youth. Psychology in the Schools. 2011; 48(7): doi: 10.1002/ pits. 20580

18. Chalamandaris AG, Piette D. School-based anti-bullying interventions: Systematic review of the methodology to assess their effectiveness. Aggression \& Violent Behavior. 2015; 24: 131-174. doi: 10.1016/j.avb.2015.04.004

19. Lehnardt K. 55 interesting facts about bullying. Web site. 
http://www.factretriever.com/bullying-facts. Accessed September 10, 2019.

20. Turner M. Being bullied throughout childhood and teens may lead to more arrests, convictions, prison time. Web site. http:// www.apa.org/news/press/releases/2013/08/being-bullied.aspx. Accessed September 10, 2019.

21. Ttofu MM, Farrington DP. Risk and protective factors, longitudinal research, and bullying prevention. New Dir Youth Dev. 2012; 133: 85-98. doi: 10.1002/yd.20009

22. Evans CBR, Frazer MW, Cotter KT. The effectiveness of school-based bullying prevention programs: A systematic review. Aggression \& Violent Behavior. 2014; 19: 532-544. doi: 10.1016/j avb.2014.07.004

23. Myers DG. Exploring Psychology. $8^{\text {th }}$ ed. NY, USA: Worth Publishers; 2011.

24. Adler A. Web site. https://pdfs.semanticscholar.org/5d5b/ d113b8702776eb0d9ed53fcb1406ff8782ca.pdf. 1930. Accessed September 10, 2019.

25. Ferguson ED. Adler's innovative contributions regarding the need to belong. The Journal of Individual Psychology. 2010; 66: 1-7.

26. Gottman J, DeClaire J. The Heart of Parenting: Raising an Emotionally Intelligent Child. NY, USA: Simon \& Schuster; 1997.

27. Greenberg LS. Coaching for emotional intelligence in parenting. In: Greenberg LS, Emotion-Focused Therapy: Coaching Clients to
Work Through Their Feelings. $2^{\text {nd }}$ ed. DC, USA: American Psychological Association; 2015: 301-327. doi: 10.1037/14692-015

28. Price-Mitchell M. Resilience: The capacity to rebuild and grow from adversity. Web site. https://www.psychologytoday. $\mathrm{com} / \mathrm{blog} /$ the-moment-youth/201507/resilience-the-capacity-rebuild-and-grow-adversity. 2015. Accessed September 10, 2019.

29. Masten AS, Monn AR. Child and family resilience: A call for integrated science, practice and professional training. Family Relations. 2015; 64: 5-21. doi: 10.1111/fare.12103

30. Gurung RAR. Health Psychology: A Cultural Approach. 3rd ed. CA, USA: Wadsworth Cengage Learning; 2014.

31. Rotheram-Borus MJ, Song J, Gwadz M, Lee M, Van Rossem R, Koopman C. Reductions in HIV risk among runaway youth. Prev Sci. 2003; 4(3): 173-187. doi: 10.1023/A:102469770

32. Olweus Bullying Prevention Program (OBPP). Web site. http://olweus.sites.clemson.edu/. 2016. Accessed September 10, 2019.

33. Majcherová K, Hajduova Z, Andrejkovic M. The role of the school in handling the problem of bullying. Aggression and Violent Behavior. 2014; 19: 463-465. doi: 10.1016/j.avb.2014.06.003

34. Adler AB, Williams J, McGurk D, Moss A, Bliese PD. Resilience training with soldiers during basic combat training: Randomisation by platoon. Appl Psychol Health Well Being. 2015; 7(1): 85-107. doi: 10.1111/aphw.12040 